\title{
Response of coloured capsicum under protective cover for different irrigation and fertilizer levels
}

\author{
U.S. KADAM, P.M. INGLE, R.T. THOKAL AND D.M. MAHALE
}

\begin{abstract}
The experiment was conducted during year 2008-09 at Hi-Tech Project, Dr. Balasaheb Sawant Konkan Krishi Vidyapeeth, Dapoli, Ratnagiri under shed net condition to study the response of coloured capsicum for different irrigation and fertilizer levels in terms of growth and yield. The study concluded that the coloured capsicum showed positive response to the different irrigation and fertilizer levels under shed net house over open field condition. The alternate day irrigation and split application of WSF fertilizers with different levels through drip irrigation system responded well by coloured capsicum in terms of growth and yield. The higher levels of irrigation and fertilizer were also boost the yield of coloured capsicum under shed net house. The study

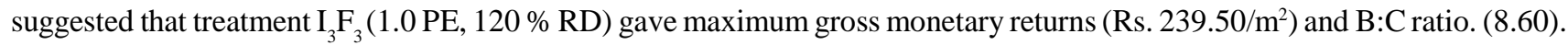

KEY WORDS : Protective cover, Shed net, Net benefits, B:C ratio, Coloured capsicum, Drip irrigation

How to cite this Article : Kadam, U.S., Ingle, P.M., Thokal, R.T. and Mahale, D.M. (2015). Response of coloured capsicum under protective cover for different irrigation and fertilizer levels. Engg. \& Tech. in India, 6 (1) : 29-34. 